\title{
Extraction of Lignin from Wheat Straw in 1, 4-Butanediol Medium Catalyzed by $\mathrm{NaOH}$
}

\author{
H.Z. Jia, Y.Z. LI, Y.K. WANG, H.Q. YIN, Q.S. ZHANG \\ Beijing Institute of Technology, Beijing, China
}

\begin{abstract}
Wheat straw lignin was extracted in 1, 4-butanediol medium catalyzed by $\mathrm{NaOH}$ for the first time. Reaction time, temperature, dosage of $\mathrm{NaOH}$ and 1, 4-butanediol, as well as volume percentage of 1,4butanediol medium were optimized to improve lignin recovery in the experiment. As a result, lignin yield was up to $74 \%$ when the reaction condition was: $10 \%(\mathrm{w} / \mathrm{w})$ of $\mathrm{NaOH}$, volume of $60 \%$ BDO medium is six times of the quality of WS, reaction time for $3 \mathrm{~h}$ at $120{ }^{\circ} \mathrm{C}$.
\end{abstract}

KEYWORD: 1, 4-butanediol; wheat straw; lignin; base catalyzed

\section{INTRODUCTION}

Cellulose, hemicelluloses, and lignin compose lignocellulosic materials and are connected to one another by covalent bonds in the cell wall (Goyal et al. 2006). Lignin is an aromatic three-dimensional network polymer found in the cell walls of biomass, which acts like glue that adheres organic tissue together. In the past few decades, lignin has been used widely for adhesives (Oiivares et al. 1988), adsorption agents (Cotoruelo et al. 2007), drugs (Reztsova et al. 2007), and phenolic resins (Kuroe et al. 2013). It is comprised of the three cross-linked phenylpropane monomer units p-hydroxyphenyl $(\mathrm{H})$, guaiacyl (G), and syringyl (S) (Vanholme et al. 2010). And the content of the three units in different botanical tissues is of certain difference (Zeng et al. 2013; Buranov et al. 2008).

Separation of lignin from biomass is of great interests to researchers nowadays. But the recalcitrant nature of lignin make it difficult to be separate out from lignocellulose (Hu et al. 2012). Many mild organosolv pulping methods such as methanol (Bland et al. 1965), ethanol (El Hage et al. 2010; Cybulska et al. 2012), 1-butanol (Pereira et al. 2007), and 1, 4-butanediol (Jia et al. 2013) (BDO) have been used to extract lignin from botanical tissues. BDO is of great interest owing to its high boiling point, low pressure and easy to be retrieved under reduced pressure (Wang et al. 2014). Some researchers has reported that lignin can be extracted from rice husk (Chen et al. 2008), bagasse (Wang et al. 2011a,b), wood (Lu et al. 2012; Cheng et al. 2004; Kishimoto et al. 2005) in a BDO medium with small amount of acid catalyst with different lignin yield. However, no reports have been published regarding the extraction of lignin from wheat straw in BDO medium catalyzed by $\mathrm{NaOH}$. In this study, an emphasis was placed on the extraction craft of lignin from wheat straw (WS) in BDO medium using $\mathrm{NaOH}$ as the catalyst in an autoclave. Factors of the extracting reaction, such as reaction time, temperature, dosage of $\mathrm{NaOH}$, were optimized in this research.

\section{METHODS AND MATERIALS}

The chemicals were used as received without further purification and were of analytical reagent grade. BDO, hydrochloric acid, toluene, ethanol and sulphuric acid were purchased from Nanjing chemical reagent Co. Ltd. (China). Sodium hydroxide was purchased from Nanjing Aojia chemical Co. Ltd. (China). Wheat straw (WS) powder (60 mesh) was purchased from Shanxi Jin He Agriculture Industry Co. Ltd. (China), and was dried at $100{ }^{\circ} \mathrm{C}$ for $6 \mathrm{~h}$ prior to use in the experiment.

\section{EXPERIMENTAL SECTION}

\subsection{Determination of lignin content in wheat straw}

The Klason lignin content in the WS powder was determined according to the standard method TAPPI T222 om-02 (TAPPI 2002). Firstly, WS (1.0 g) refluxed with $200 \mathrm{ml}$ ethanol-toluene mixture $(\mathrm{v} / \mathrm{v}=$ 
1: 2) in a Soxhlet extractor for $8 \mathrm{~h}$ to remove resin, wax, and fat. Secondly, the solid was air dried in a fume hood. Next, the dried solid was suspended in $15 \mathrm{~mL} 72 \% \mathrm{H}_{2} \mathrm{SO}_{4}$ in a $100 \mathrm{ml}$ beaker under magnetic stirring. After $4 \mathrm{~h}$ stirring at room temperature, the mixture was diluted with $560 \mathrm{ml}$ deionized water, boiled and refluxed for $4 \mathrm{~h}$, and cooled to room temperature. The solution was left undisturbed overnight and then filtered. The filtered residue was washed with deionized water (DIW) until the $\mathrm{pH}$ was 7 . The lignin residual was freezedried and weighed. Klason lignin measurements were performed in triplicate. The lignin content of wheat straw was determined as $19 \pm 0.1 \%$ (eq. (1)).

$$
\begin{aligned}
& \mathrm{X}=(A / W) \times 100 \% \\
& \mathrm{Y}=\left(A^{\prime} / W^{\prime}\right) \times 100 \%
\end{aligned}
$$

(1) Where $X=$ Lignin content in WS, A = weight of lignin output, and $\mathrm{W}=$ oven-dry weight of WS. The theoretical yield of lignin output was 19\%; (2) where $\mathrm{Y}=$ Lignin yield, $\mathrm{A}^{\prime}=$ weight of lignin recovered, and $\mathrm{W}^{\prime}=$ weight of lignin theoretical output.

\subsection{Lignin separation from WS by $\mathrm{NaOH}$}

$25 \mathrm{~g}$ of wheat straw was added to a $1 \mathrm{~L}$ autoclave reactor and mixed with 150 to $375 \mathrm{ml}$ of BDO (from $0 \%$ to $100 \%, \mathrm{v} / \mathrm{v}$ ) medium and 0.5 to $3.75 \mathrm{~g}$ of $\mathrm{NaOH}$, reaction time for 1 to $4 \mathrm{~h}$, temperature range from 120 to $200{ }^{\circ} \mathrm{C}$. The flow chart of the extraction process is shown in Figure 1. Adding hydrochloric acid to regulate $\mathrm{pH}$ to 2 . The lignin residual was freeze-dried with the vacuity less than $20 \mathrm{~Pa}$.

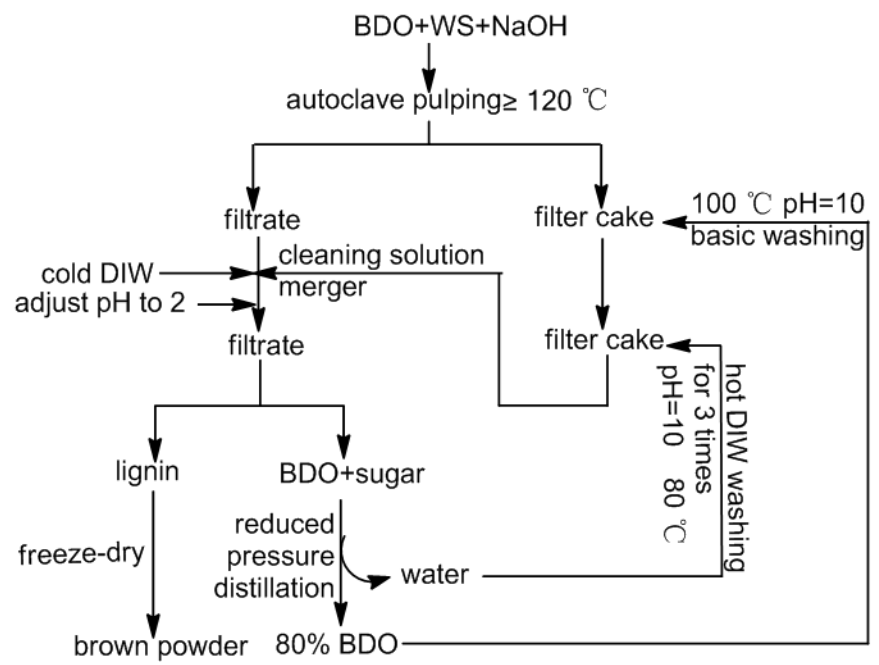

Figure 1. Extraction of lignin from WS catalyzed by $\mathrm{NaOH}$ (WS: wheat straw; DIW: deionized water; BDO: 1, 4butandiol; "+" denotes mixing)

\section{RESULTS AND DICUSSION}

Figure 2 showed the effect of reaction temperature (a) and liquid / WS ratio (b) on lignin yield. The trend of the two curves are similar. Exactly, Lignin recovery decreased as the temperature escalated as well as liquid / WS ratio increased. This may be because when temperature was up beyond $120{ }^{\circ} \mathrm{C}$, lignin was decomposed by $\mathrm{NaOH}$ in BDO medium. And when liquid / WS ratio was far beyond 6, lignin dissolved in BDO medium, resulted in a lower lignin recovery. When liquid/WS ratio was 6 , the reactants was dense enough to be fetched out of the autoclave. So the optimum reaction temperature was $120^{\circ} \mathrm{C}$, and the optimum liquid/WS ratio was 6 , with the highest yield $74 \%$.
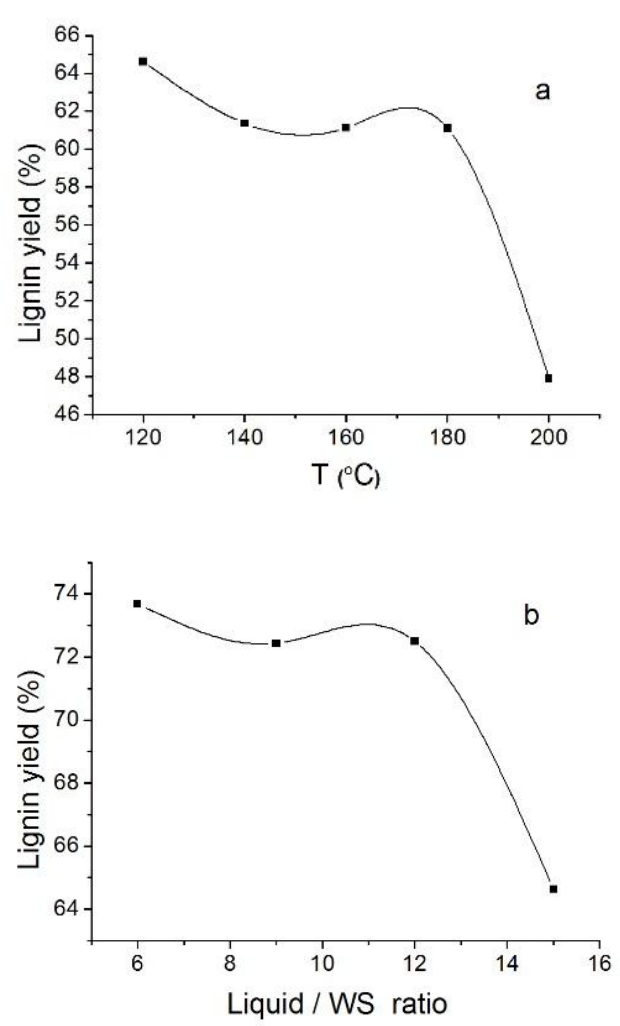

Figure 2. $a$. The effect of reaction temperature on lignin yield. Conditions: $25 \mathrm{~g}$ of WS, $2.5 \mathrm{~g}$ of $\mathrm{NaOH}, 300 \mathrm{ml} 80 \%$ (v/v) $\mathrm{BDO}$, reaction time for $3 \mathrm{~h} ; b$. The effect of liquid / WS ratio on lignin yield. Conditions: $25 \mathrm{~g}$ of WS, $2.5 \mathrm{~g}$ of $\mathrm{NaOH}, 150$ to $375 \mathrm{ml} \mathrm{60 \%} \mathrm{(v/v)} \mathrm{BDO,} 120{ }^{\circ} \mathrm{C}$, reaction time for $3 \mathrm{~h}$.

As shown in Figure 3a, the curve displays the highest value at $20 \%(\mathrm{v} / \mathrm{v})$ BDO medium. However, it took very long time to finish reduced pressure filtration. And when the volume percentage of BDO medium was increased to $60 \%$, filtration was easy to carry out. This manifested that the existence of BDO medium contribute to filtration speed. The optimum volume percentage of BDO medium was $60 \%$, with lignin yield up to $72.4 \%$. The curves depicted in Figure $3 \mathrm{~b}$ and Figure $3 \mathrm{c}$ showed very similar trend that ordinate values increased first and then decreased as abscissa value extending. As shown in Figure $3 b$, when the dosage of $\mathrm{NaOH}$ was $10 \%$ 
(w/w) of WS, lignin yield reached the highest value $72.5 \%$. This may be because when $\mathrm{NaOH}$ was less than $10 \%, \mathrm{NaOH}$ was inadequate to cleave the $\mathrm{C}-\mathrm{O}$ bonds between lignin and cellulose, and when $\mathrm{NaOH}$ was more than $10 \%, \mathrm{NaOH}$ catalyzed the polymerization of lignin fragments with lignin combined with cellulose. So the optimum dosage of $\mathrm{NaOH}$ was $10 \%(\mathrm{w} / \mathrm{w})$. In Figure 3c, Lignin yield reached the highest value $64.6 \%$ when reaction time was $3 \mathrm{~h}$. when reaction time beyond $3 \mathrm{~h}$, lignin fractions integrated to the lignin which still combined with cellulose or partly degraded to small molecules which cannot be precipitated out after treatment. Owing to the above, the optimum reaction time was fixed at $3 \mathrm{~h}$.
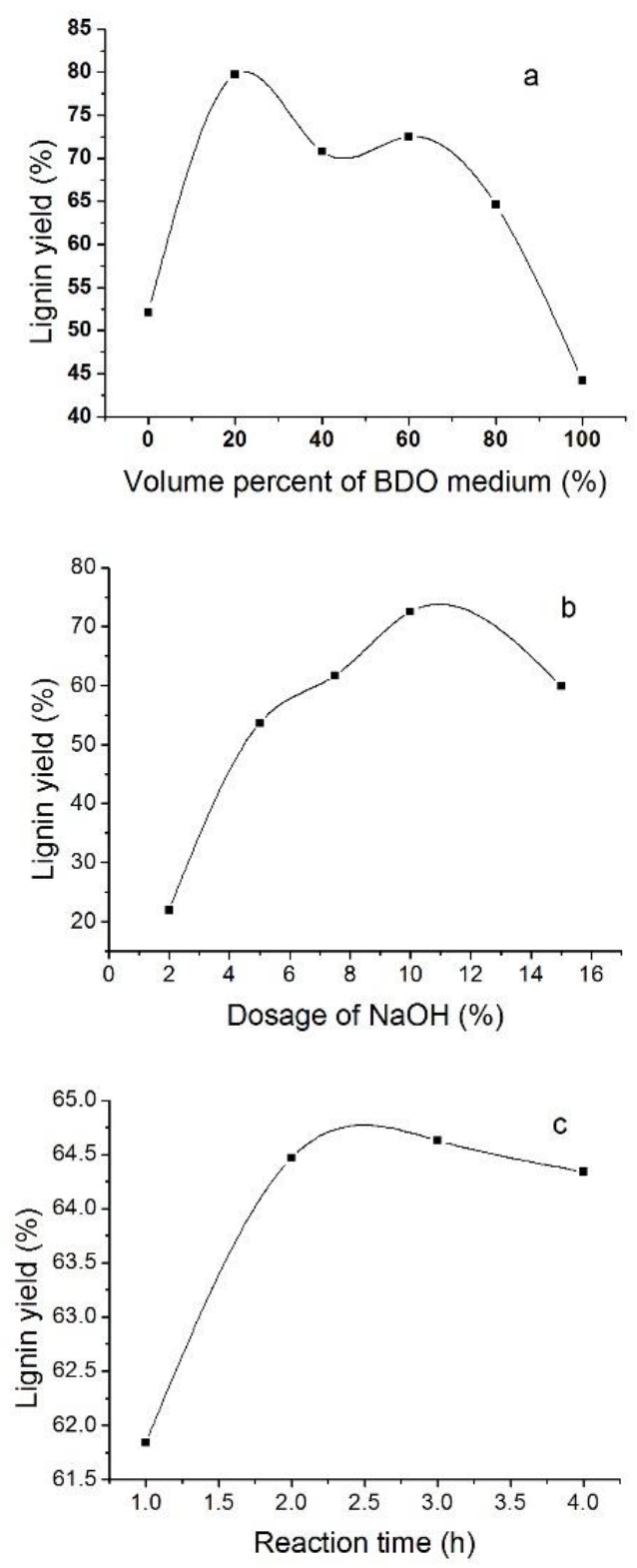

Figure 3. $a$. The effect of volume percentage of BDO medium on lignin yield. Conditions: $25 \mathrm{~g}$ of WS, $2.5 \mathrm{~g}$ of $\mathrm{NaOH}, 300 \mathrm{ml}$ $\mathrm{x} \%(\mathrm{v} / \mathrm{v}) \mathrm{BDO}, 120{ }^{\circ} \mathrm{C}$, reaction time for $3 \mathrm{~h} ; b$. The effect of the dosage of $\mathrm{NaOH}$ on lignin yield. Conditions: $25 \mathrm{~g}$ of WS, $2.5 \mathrm{~g}$ of $\mathrm{NaOH}, 300 \mathrm{ml} 60 \%(\mathrm{v} / \mathrm{v}) \mathrm{BDO}, 120{ }^{\circ} \mathrm{C}$, reaction time for $3 \mathrm{~h} ; c$. The effect of reaction time on lignin yield. Conditions: $25 \mathrm{~g}$ of WS, $2.5 \mathrm{~g}$ of $\mathrm{NaOH}, 300 \mathrm{ml} 80 \%(\mathrm{v} / \mathrm{v})$ BDO, $120{ }^{\circ} \mathrm{C}$.

\section{CONCLUSION}

The optimum condition to extract lignin from wheat straw was as follows: $10 \%(\mathrm{w} / \mathrm{w})$ of $\mathrm{NaOH}$, the volume of $60 \%$ BDO medium is six times of the quality of WS, reaction time for $3 \mathrm{~h}$ at $120{ }^{\circ} \mathrm{C}$. Lignin yield was up to $74 \%$ under the optimum condition, which was comparable to other lignin extraction process (Chen \& Liu 2007). BDO medium can be retrieved completely for recycling through reduced pressure distillation. This was a totally environmental friendly process to be carried out.

\section{ACKNOWLEDGEMENT}

Thanks to the research funds provided by Anhui Sealong Biotechnology Co. Ltd..

\section{REFERENCES}

[1] Bland, D.E. \& Menshun, M. 1965. The combination of ellagic acid with lignin during high temperature methanol extraction of eucalyptus wood. Holzforschung 19(2): 3336.

[2] Buranov, A.U., and Mazza, G. 2008. Lignin in straw of herbaceous crops. Ind. Crops Prod. 28(3): 237-259.

[3] Chen H.Z. \& Liu L.Y. 2007. Unpolluted fractionation of wheat straw by steam explosion and ethanol extraction. Bioresour. Technol. 98(3): 666-676.

[4] Chen, Y.P. \& Cheng, X.S. 2008. Preparation and characteristic analysis of rice husk high boiling solvent lignin. Journal of Forestry Research 19(2):159-163.

[5] Cheng X.S., Chen W.J., Chen Y.P., Chen Y.X., Li M.J., \& Fang H.S. 2004. Preparation and properties of hbs lignin from masson pine. Chemical research in chinese universities 20(2):225-228.

[6] Cotoruelo, L.M., Marques, M.D., Diaz, F.J., Cordero, T. \& Rodriguez, J.J. 2007. Activated carbons from lignin: Their application in liquid phase adsorption. J. Sep. Sci. Technol. 42(15): 3363-3389.

[7] Cybulska, I., Brudecki, G., Rosentrater, K., Julson, J.L. \& Lei, H.W. 2012. Comparative study of organosolv lignin extracted from prairie cordgrass, switchgrass and corn stover. Bioresour. Technol. 118: 30-36.

[8] El Hage, R., Brosse, N., Sannigrahi, P. \& Ragauskas, A. 2010. Effects of process severity on the chemical structure of miscanthus ethanol organosolv lignin. Polym. Degrad. Stab. 95(6): 997-1003.

[9] Goyal, H.B., Seal, D. \& Saxena, R.C. 2006. Bio-fuels from thermochemical conversion of renewable resources: A review. Renewable \& sustainable energy reviews 12: 504-517.

[10] Hu, G., Cateto, C., Pu, Y.Q., Samuel, R. \& Ragauskas A. J. 2012. Structural characterization of switchgrass lignin after ethanol organosolv pretreatment. Energy Fuels 26(1): 740-745.

[11] Jia J., Qu, Y.G., Yuan, Y.P., Wang, K.K., Yang, F., Wu, G.F. \& Li, Y.F. 2013. Separation of lignin from pine-nut hull by the method of HBS and preparation of ligninPEG-PAPI. Appl. Mech. Mater. 320:429-434. 
[12] Kishimoto, T., Ueki, A., Takamori, H., Uraki, Y. \& Ubukata, M. 2005. Delignification mechanism during high-boiling solvent pulping. Part 6: Changes in lignin structure analyzed by $1 \mathrm{H}-13 \mathrm{C}$ correlation 2-D NMR spectroscopy. Holzforschung 58(4): 355-362.

[13] Kuroe, M., Tsunoda, T., Kawano, Y. \& Takahashi, A. 2013. Application of lignin-modified phenolic resins to brake friction material. J. Appl. Polym. Sci. 129(1): 310315.

[14] Lu, Q., Liu, W.J., Yang, L., Zu, Y.G., Zu, B.S., Zhu, M.H., Zhang, Y., Zhang, X.N., Zhang, R.R., Sun, Z., Huang, J.M., Zhang, X.N. \& Li, W.G. 2012. Investigation of the effects of different organosolv pulping methods on antioxidant capacity and extraction efficiency of lignin. Food Chemistry. 131(1): 313-317.

[15] Oiivares, M., Guzmfin, J.A., Natho, A. \& Saavedra, A. 1988. Kraft lignin utilization in adhesives. Wood Sci. Technol. 22(2): 157-165.

[16] Pereira, A.A., Martins, G.F., Antunes, P.A., Conrrado, R., Pasquini, D., Job, A.E., Curvelo, A.A.S., Ferreira, M., Riul, A. \& Constantino, C.J.L. 2007. Lignin from sugar cane bagasse: Extraction, fabrication of nanostructured films, and application. Langmuir 23(12): 6652-6659.
[17] Reztsova, V.V. 2007. Potential of lignin application in development of new antitumor drugs. Vopr. Onkol. 53(5): 505-509 (in Russian)

[18] TAPPI T222 om-02. 2002. Acid-insoluble lignin in wood and pulp. Tappi Press, Atlanta, GA.

[19] Vanholme, R., Demedts, B., Morreel, K., Ralph, J. \& Boerjan, W. 2010. Lignin biosynthesis and structure. Plant Physiol. 153(3): 895-905.

[20] Wang, Q., Chen, K.F., Li, J., Yang, G.H., Liu, S.S. \& Xu, J. 2011a. The solubility of lignin from bagasse in a 1,4butanediol/water system. Bioresour. 6(3):3034-3043.

[21] Wang, Q., Chen, K.F., Liu, S.S., Li, J. \& Xu, J. 2011 b. Kinetics of bagasse delignification by using high-boiling solvent. Bioresour. 6(3):2366-2374.

[22] Wang, Q., Liu, S.S., Yang, G.H. \& Chen, J.C. 2014. Characterization of high-boiling-solvent lignin from hotwater-extracted bagasse. Energy Fuels 28(5): 3167-3171.

[23] Zeng, J.J., Gregory, L. Helms, Gao, X. \& Chen, S.L. 2013. Quantification of wheat straw lignin structure by comprehensive NMR analysis. J. Agric. Food Chem. 61(46): 10848-10857. 